\title{
Gender disparities in health at older ages and their consequences for well-being in Latin America and the Caribbean
}

\author{
Marília R. Nepomuceno ${ }^{1, *}$, Vanessa di Lego ${ }^{2}$, and Cássio M. Turra ${ }^{3}$
}

\begin{abstract}
Women live longer but can expect to spend more years in poorer health compared to men. In the context of population aging and declining gender ratios at older ages, there are increasing concerns about how this disadvantage in female health will affect well-being and sustainability, particularly in developing regions that are rapidly aging. Our study compares differences in health expectancies at older ages for men and women in order to assess gender disparities in health. We use data from the Survey on Health, Well-Being, and Aging in Latin America and the Caribbean to decompose the gender gap into total and age-specific mortality and disability effects in seven cities in the region. Our results show that at older ages, higher disability rates among women reduced the gender gap in healthy life expectancy by offsetting women's mortality advantage. In addition, we find that women's mortality advantage decreased almost systematically with age, which reduced the contribution of the mortality effect to the gender gap at older ages. Although the gender gap in health followed a similar pattern across the region, its decomposition into mortality and disability effects reveals that there was substantial variation among cities. Thus, across the region, the implications of the gender gap in health for well-being vary, and the policies aimed at reducing this gap should also differ.
\end{abstract}

Keywords: gender gap; healthy life expectancy; disability; older ages; Latin America and the Caribbean; decomposition

\footnotetext{
${ }^{1}$ Max Planck Institute for Demographic Research, Rostock, Germany

${ }^{2}$ Vienna Institute of Demography (OeAW), Wittgenstein Centre for Demography and Global Human Capital (IIASA, OeAW, University of Vienna), Vienna, Austria

${ }^{3}$ Demography Departament - Cedeplar, Universidade Federal de Minas Gerais, Belo Horizonte, Brazil

${ }^{*}$ Correspondence to: Marília R. Nepomuceno, nepomuceno@demogr.mpg.de
} 


\section{Introduction}

Promoting health and well-being at older ages is one of the three priority areas established in the 2002 Madrid International Plan of Action on Ageing (MIPAA) to ensure that population aging is sustainable and equitable (World Health Organization 2004). It is also one of the 17 Sustainable Development Goals (SDGs), which extended the target to all ages (United Nations Development Programme 2015). However, countries face a number of challenges in meeting and monitoring progress toward those goals, including unique preexisting gender- and age-specific disparities in health and mortality that directly affect well-being. Scholars have examined these gaps across several countries in different parts of the world (Jagger and Matthews 2002; Oksuzyan et al. 2008; Nusselder et al. 2010). It appears, however, that the consequences of these gaps are more dramatic in countries with rapidly aging populations where inequality levels are high and long-term care is provided informally by families, as is the case in many Latin American countries (Palloni and McEniry 2007; United Nations 2017). Moreover, due to the high levels of socioeconomic inequality in the region, early-life conditions in these countries are often poor. As these conditions are predictive of disability at older ages, they may increase the burden of health for older people, and negatively affect their well-being (Monteverde et al. 2009). Thus, in Latin America and the Caribbean, the speed of population aging has outstripped the ability of societies to solve old and new social, economic and health issues (Turra and Fernandes 2020).

Even though gender disparities in health have been extensively studied worldwide (Case and Paxson 2005; Crimmins and Kim 2010; Andrade et al. 2011; di Lego et al. 2020; Grundy 2006; Jacobsen et al. 2008; Mathers et al. 2001; Oksuzyan et al. 2014; Verbrugge 1989; Yong et al. 2010), there has been no conclusive explanation for why, despite living longer than men, women perform worse in terms of their disability, chronic morbidity and self-rated health outcomes (Crimmins et al. 2002; Luy and Minagawa 2014; Robine et al. 2001; Spiers et al. 2003). Compared to men, women have higher morbidity from acute conditions, nonfatal chronic diseases and short-term disabilities (Green and Pope 1999; Verbrugge 1985). The rate of decline in physical functioning is also higher among women, with women being outperformed by men across all ages on tests of hand grip strength (Leong et al. 2015; Sanderson and Scherbov 2014), walking speed and standing balance (Keevil et al. 2013). Moreover, compared to men, women are less likely to recover once disabled (Beckett et al. 1996), and they are more likely to use health care services (Green and Pope 1999; Redondo-Sendino et al. 2006) and prescription and nonprescription drugs (Roe et al. 2002). Studies have shown that these gender differences are consistent across countries and at older ages; with the exception of the pattern of gender differences in depressive symptoms, which appears to be more country-specific (Oksuzyan et al. 2010). Because men have higher mortality than women at all ages and for many leading causes of death, it is puzzling that the proportion of life spent in good health is higher for men than for women (Crimmins and Saito 2001; Nusselder et al. 2010; Rieker and Bird 2005; Van Oyen 
et al. 2013). These contradictions in the mortality-morbidity differences between the genders have led to numerous studies describing this phenomenon as the "gender and health paradox" (Rieker and Bird 2005), the "morbidity paradox" (Gorman and Read 2006), the "morbidity-mortality paradox" (Kulminski et al. 2008) or the "male-female health-survival paradox" (Oksuzyan et al. 2008).

Studies conducted in Latin American and the Caribbean (LAC) countries have systematically described women as suffering from excess morbidity, despite having higher longevity (Andrade et al. 2014; Camargos et al. 2007; Palloni and McEniry 2007; Zunzunegui et al. 2009). In LAC, women are more likely than men to report poor self-rated health, and the prevalence of disability is around 50\% higher among women than among men (Barbosa et al. 2005; Duarte et al. 2005). In terms of the gender gap in healthy life expectancy, the pattern in LAC is similar to the pattern that has been documented in the wealthiest regions: i.e., women live longer than men, but the proportion of time they spend living with a disability is greater (Andrade et al. 2011; Camargos et al. 2008). Although these previous studies have shown that there are health disparities between men and women at older ages, the specific contributions of mortality and disability to these gender disparities in health expectancy remain unclear (Angel et al. 2017; Campos et al. 2015; Andrade et al. 2011; Wong et al. 2005).

There are several ways to measure gender disparities in health, including health expectancy. This summary measure is widely used to evaluate the average level of population health (Murray et al. 2002). In addition, it is a policy planning tool that is generally used to compare the level of health across populations (Nusselder et al. 2010; Robine et al. 2009; Van Oyen et al. 2010; Yokota et al. 2019). Decomposition analyses of the contributions of mortality and disability to the gender gap in health expectancy in high-income countries have suggested that considerable gender differences in mortality and disability can be masked when only the total gap is analyzed (Mairey et al. 2014; Nusselder et al. 2010; Nusselder and Looman 2004; Van Oyen et al. 2013). For example, decomposition analyses conducted in the Netherlands found there are substantial effects of mortality (3.1 years) and disability ( -3.5 years) by gender; but also that because the two effects work in opposite directions, they result in a small net gap ( -0.4 years). Therefore, when examining the gender gap in health expectancy, it is important to focus not only on the total gender gap, but also on the contributions of its components. This approach is crucial for targeting policy priorities, particularly those that seek to reduce health differentials by subgroups.

Our study aims to compare differences in the health expectancies of men and women across large cities in seven countries in Latin America and the Caribbean: Argentina, Brazil, Chile, Mexico, Uruguay, Cuba and Barbados. We use information from the Survey on Health, Well-Being, and Aging in Latin America and the Caribbean (SABE) to examine whether the gender gap in health expectancy follows a similar pattern across those countries, and to estimate the contributions of disability and mortality by age. We then discuss the consequences of these findings for monitoring overall health and well-being in the region. By 2050, 198 million people 
aged 60 years or older will be living in Latin America and the Caribbean, with a ratio of 84 men per 100 women (United Nations 2017). Therefore, understanding the mechanisms that contribute to morbidity and mortality differentials among older individuals in such contexts is critical for improving the health and well-being of these individuals, and for meeting the Sustainable Development Goals.

\section{Gender differences in health and mortality across LAC countries}

The overall pattern of gender differences in healthy life expectancy across countries in LAC is similar to the patterns observed in higher-income countries: i.e., women live longer than men, but the proportion of time they spend living with a disability is greater (Andrade et al. 2011; Camargos et al. 2008). However, the specific contributions of mortality and health to these differentials remain unclear. In addition, the LAC region, and specifically the SABE countries analyzed here, have mortality and health characteristics that make it particularly challenging to determine what drives these gender gaps, and their magnitudes (Angel et al. 2017; Campos et al. 2015; Andrade et al. 2011; Wong et al. 2005).

The health and mortality conditions that underlie these observed gender disparities vary considerably across the region. For example, it has been shown that in Chile, musculoskeletal disorders and fall-related fractures play an important role in health differences by gender, as the prevalence of osteoarthritis is twice as high among older women as among older men, independent of their socioeconomic position (Moreno et al. 2018; Murtagh and Hubert 2004). Similarly, the prevalence of osteoporosis is more than five times higher among women than among men, with women reporting more frequent falls (Albala et al. 2011). In Mexico, by contrast, obesity and diabetes appear to be the most critical factors, especially at ages $70-75$, as in this age group, the share of women with diabetes is high (29\%), and the percentage of women with obesity is significantly higher than that of men (26.7\% vs. 22.3\%) (Wong et al. 2015). Both diabetes and obesity are risk factors for a series of chronic conditions, and are associated with the incidence of multiple comorbidities, including type II diabetes, cancer, and cardiovascular diseases (Guh et al. 2009; Kearns et al. 2014). On the other hand, Cuba, despite being the country with the lowest levels of diabetes and obesity in the Latin American and Caribbean region (Palloni and McEniry 2007), has high prevalence levels of acute myocardial infarction, with men having a higher risk of dying from this cause than women of the same age (Armas et al. 2012). Moreover, the incidence of lung cancer and the mortality risk associated with it has increased among older men in LAC (Galán et al. 2009). Bridgetown (Barbados) has struggled over the past decade with a very high burden of deaths from liver cirrhosis attributed to alcohol abuse and heavy smoking among men (Moonie and Quashie 2011). In Brazil, gender differences in disability severity and in levels of life-threatening conditions seem to contribute 
more to the gender gap in healthy life expectancy. It has, for example, been reported that compared to their male counterparts, Brazilian women are more likely to be disabled, and to have more severe disabilities (Camargos et al. 2007; Camargos et al. 2008; Andrade et al. 2011). It has also been shown that in Brazil, unhealthy life expectancy is higher among women than among men at all ages, and that a woman at age 60 can expect to live two years longer with severe limitations than a man at the same age. These findings imply that Brazilian women live proportionally more years with severe limitations than men (Belon et al. 2014; Nepomuceno and Turra 2012; Parahyba et al. 2005). Evidence for higher-income countries indicates that for men, having severe limitations is associated with a higher mortality risk. Thus, gender differences in mortality in these countries may be explained by gender differences in the effects these conditions have on mortality (Case and Paxson 2005). This might also be the case for Brazil.

There are significant differences in the socioeconomic, demographic and health conditions of the countries in which the SABE was conducted. For example, despite not being the wealthiest country in the LAC region, Cuba has been prioritizing health for almost half a century. The country has an extensive primary health care network, a long history of controlling infectious diseases, relatively low infant mortality, and below replacement level fertility since 1978. Thus, the aging process in Cuba is very advanced (Franco et al. 2007a). The trajectory of Bridgetown resembles that of Cuba in terms of the stage of the demographic transition and the efficiency of the public health care system (Hennis et al. 2005). In Bridgetown, life expectancy at birth in 2001 was 76.9 years, and was thus higher than the average of 70.3 years for the entire region (Knight et al. 2004). In addition, of the SABE cities, Bridgetown has the highest proportion of women aged 75+ (Palloni and McEniry 2007). Interestingly, Uruguay has the lowest poverty and urban economic inequality levels in Latin America (urban Gini $=0.44,10 / 40$ ratio $=8.8$ ), spends the most per capita on medical care, and had the lowest rate of poverty among the elderly population in the year 2000 (Wallace and Gutiérrez 2005). Nonetheless, in the early 2000s, Uruguay had one of the lowest remaining life expectancies at age 60 for men, and one of the highest for women, in the LAC region (United Nations 2019). It has also been shown that older Mexicans account for more than $50 \%$ of families living in extreme poverty; i.e., households living on one dollar a day or less. As women live longer than men, higher proportions of women than of men are living in poverty, which may contribute to the higher levels of disability among women (Angel et al. 2017; Huenchuan 2013).

Social inequality in health care services, expected outpatient medical care, and hospital admissions also vary across SABE cities. Inequalities in health care access are less marked in Cuba, Argentina and Uruguay, but are more pronounced in Brazil and Mexico. Previous research has indicated that these inequalities have resulted in somewhat puzzling health care patterns across the region (Noronha and Viegas 2005). For instance, given the relatively high level of income inequality in Brazil and the lower level in Uruguay, equity in access to care for older people was found to be better than expected in Brazil and worse than expected in Uruguay. 
Not surprisingly, inequity in access to care was attributed mainly to low levels of health insurance coverage in Mexico and to differences in socioeconomic status in Chile (Wallace and Gutiérrez 2005). Finally, excess mortality from external causes (homicide, motor vehicle accidents and suicide) among men aged 15-29 is much higher in these countries than it is in developed countries. LAC countries have the highest homicide rates for young men in the world. Thus, external causes of death have contributed to significant changes in life expectancy in the LAC region, and have hindered improvements in male longevity (Canudas-Romo and Aburto 2019; Acosta et al. 2018). All of these factors make it particularly challenging to understand how mortality and health are contributing to gender disparities in healthy life expectancy in LAC countries, and what is driving those observed differences.

\section{Data and methods}

The data come from the Survey on Health, Well-Being, and Aging in Latin America and the Caribbean (SABE) (Pelaez et al. 2006). The SABE interviewed noninstitutionalized representative samples of individuals aged 60 and older in seven cities in Latin America and the Caribbean in 1999-2000. Table 1 presents the number of respondents by age group and city in 1999-2000. For some cities, such as São Paulo, the survey has a longitudinal design, with other data collection waves taking place in 2006 and 2010 (Lebrão et al. 2018). Unfortunately, the longitudinal study was not carried out in all cities, which prevents us from performing trend analyses. Therefore, we can only perform cross-city comparisons for the year 2000.

The SABE sample is limited to urban areas, which restricts our ability to generalize our results to the total population. However, as previous research has shown that the demographic profiles of the samples are close to the national averages, our results should not diverge too dramatically from those for the general population (Palloni and McEniry 2007; Wong et al. 2005).

In this study, we compare estimates for the seven cities included in the 2000 survey: Buenos Aires (Argentina), São Paulo (Brazil), Santiago (Chile), Mexico City (Mexico), Montevideo (Uruguay), Havana (Cuba) and Bridgetown (Barbados). The most significant advantages of the SABE are the consistency and the comparability of the data across countries, with the surveys being translated into three different languages (Spanish, Portuguese and English); and the high rates of response. Havana had the highest response rate $(95 \%)$, followed by Bridgetown $(85 \%)$, São Paulo (85\%), Mexico City (85\%) and Chile (84\%). The response rates in Montevideo and Buenos Aires were somewhat lower, at $66 \%$ and $60 \%$, respectively (Palloni and McEniry 2007).

To measure health status, we use the question that evaluates functional limitations based on the Katz Index of Independence in Activities of Daily Living: i.e., limitations in bathing, dressing, toileting, walking across a room, eating and getting in and out of bed. Thus, the question covers the fundamental skills typically required to manage an individual's basic physical needs, and is comparable to the questions 
Table 1:

SABE sample size by age and city, 2000

\begin{tabular}{lccccccc}
\hline & \multicolumn{7}{c}{ Sample size } \\
\cline { 2 - 8 } $\begin{array}{l}\text { Age } \\
\text { Group }\end{array}$ & $\begin{array}{c}\text { Bridgetown } \\
\text { (Barbados) }\end{array}$ & $\begin{array}{c}\text { Buenos Aires } \\
\text { (Argentina) }\end{array}$ & $\begin{array}{c}\text { Havana } \\
\text { (Cuba) }\end{array}$ & $\begin{array}{c}\text { Mexico City } \\
\text { (Mexico) }\end{array}$ & $\begin{array}{c}\text { Montevideo } \\
\text { (Uruguay) }\end{array}$ & $\begin{array}{c}\text { Santiago } \\
\text { (Chile) }\end{array}$ & $\begin{array}{c}\text { São Paulo } \\
\text { (Brazil) }\end{array}$ \\
\hline $60-64$ & 283 & 241 & 483 & 383 & 317 & 291 & 426 \\
$65-69$ & 340 & 252 & 402 & 310 & 366 & 327 & 379 \\
$70-74$ & 300 & 252 & 349 & 230 & 330 & 240 & 336 \\
$75-79$ & 264 & 160 & 257 & 156 & 242 & 209 & 472 \\
$80-84$ & 177 & 84 & 207 & 98 & 124 & 128 & 307 \\
$85+$ & 144 & 54 & 207 & 70 & 71 & 106 & 223 \\
Total & 1,508 & 1,043 & 1,905 & 1,247 & 1,450 & 1,301 & 2,143 \\
\hline
\end{tabular}

Source: SABE.

used in other surveys of older people, particularly the Health and Retirement Survey (HRS) (2002). We define as disabled those individuals who answered "yes" to at least one of the following questions: "Do you have difficulty bathing?"; "Do you have difficulty dressing?"; "Do you have difficulty using the toilet?"; "Do you have difficulty walking across a room?; "Do you have difficulty eating?"; and "Do you have difficulty getting in and out of a bed?" This definition is in line with the recommendations in previous studies that used ADLs from the SABE (Albala et al. 2005; Palloni et al. 2002; Palloni and McEniry 2007).

Information on the prevalence of disability for each city drawn from the SABE is combined with city-specific life tables by sex in 2000. The exception is Bridgetown, for which we use a national life table. All of the mortality data were generously provided by Flavia Andrade, who estimated them for an earlier article (Andrade 2009). Since SABE is a sample survey, we calculate the proportion of disabled individuals in the sample, and compute a 95\% binomial confidence interval for the disabled proportion. The confidence intervals rely on approximating the binomial distribution with a normal distribution. This approximation is based on the central limit theorem, and, since our samples are large, it is reliable. Using this approach, we are able to present a range of values for measures derived from the SABE data.

To examine gender disparities in health expectancy, we estimate the disability-free life expectancy (DFLE) using the Sullivan Method (Sullivan 1971), a methodological approach that has been used before in similar analyses (e.g., Crimmins et al. 2016). For each age group, we estimate the prevalence of disability from SABE data and combine it with the total number of person-years lived obtained from life tables, in order to disentangle the number of years lived with and without disability. The number of person-years lived free of disability is calculated as,

$$
{ }_{n} L_{x}^{i}={ }_{n} L_{x}\left(1-{ }_{n} \pi_{x}\right)
$$


where ${ }_{n} L_{x}^{i}$ is the number of person-years lived without disability between ages $x$ and $x+n,{ }_{n} L_{x}$ is the total number of person-years lived in the age group $x$ and $x+n$, and ${ }_{n} \pi_{x}$ is the proportion of disabled individuals in the age group $x$ and $x+n$.

Then, life expectancy free of disability (DFLE) is calculated as,

$$
D F L E_{x}=\frac{\sum_{k=x}^{w}\left({ }_{n} L_{k}^{i}\right)}{\ell_{x}}
$$

where $D F L E_{x}$ is the number of years lived without disability at age $x, w$ is the starting age of the open age interval, and $\ell_{x}$ is the number of survivors at age $x$.

We then calculate gender gap in DFLE as,

$$
\Delta_{x}=D F L E_{x}^{\text {Women }}-D F L E_{x}^{\text {Men }},
$$

and split the gender differences in DFLE at age $x$ into mortality and disability effects by five-year age groups. To decompose the gap, we apply the continuous change decomposition method that was developed by Horiuchi et al. (2008) and implemented in R by Riffe (2018). The continuous change decomposition method assumes that covariates (e.g., age-specific mortality rates and age-specific prevalence of disability) change continuously along an actual or hypothetical dimension, such as between two periods or between two populations, thereby modifying aggregate measures such as life expectancy and healthy life expectancy. Each of these tiny changes in the aggregate indices can be approximated by a linear combination of $n$ partial derivatives of the function with respect to the covariates (Horiuchi et al. 2008). Then, numerical integration is used to obtain the total contribution of the covariates for the variation of the aggregate measure. This method is very flexible, and can be used for decomposing gaps in different aggregate measures, including healthy life expectancy, as presented by van Raalte and Nepomuceno (2020).

\section{Results}

Figure 1 compares life expectancy at age 60 for women and men. Not surprisingly, the results indicate that women were living longer than men in all cities. Among women, life expectancy at age 60 varied from 21.9 in São Paulo (Brazil) to 24 years in Santiago (Chile). Among men, the estimates show more variation across cities, ranging from 17.2 years (São Paulo) to 20.3 years (Mexico City). The gender gap (women-men) in life expectancy was larger for the four cities (São Paulo, Buenos Aires, Bridgetown and Montevideo) where male life expectancy at age 60 was below 18 years.

Among women, the mortality advantage contrasted with a disability disadvantage. Figure 2 shows the differences in the prevalence of disability between women and men aged 60 and older in each city. In all cities, the prevalence rates were higher for women than for men. Buenos Aires and Santiago were the cities with the largest 
Figure 1:

Total life expectancy (LE) at age 60 and the size of the gender gap in life expectancy (women-men), by city, 2000

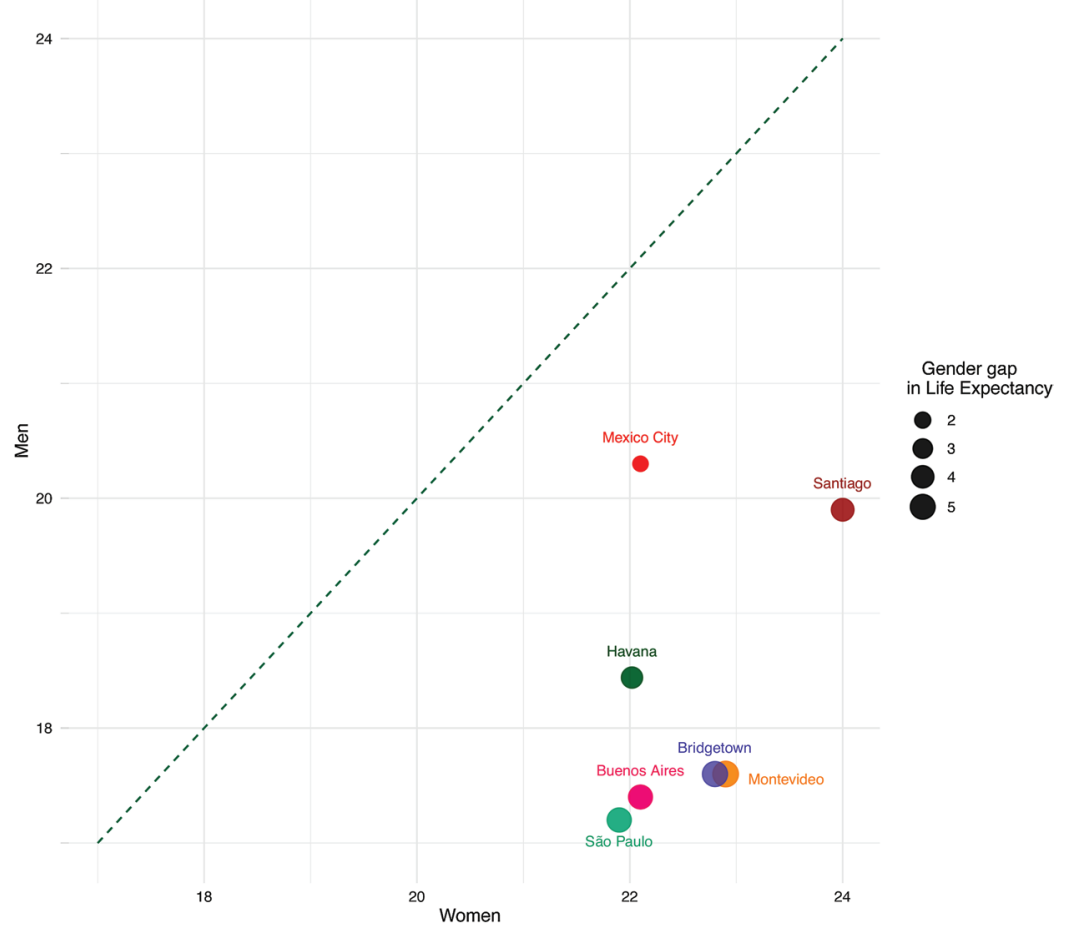

Note: The dashed line corresponds to equal life expectancies at age 60 for men and women.

Source: Own elaboration using data from Andrade (2009).

differences by gender. Meanwhile, São Paulo had the lowest variation in disability by gender.

The gender differences in mortality and disability can be examined simultaneously by estimating and decomposing the gender gap in life expectancy. Table 2 shows total life expectancy (LE), disability-free life expectancy (DFLE), and life expectancy with disability (LEWD) at age 60 for the seven LAC cities in the year 2000. As expected, we can see that in all cities, the gender differences in LE favored women. The largest gap in LE at age 60 was in Montevideo (5.30 years), followed by in Bridgetown (5.10 years), São Paulo (4.70 years), Buenos Aires (4.60 years), Santiago (4.10 years), Havana (3.58 years) and Mexico City (1.80 years). Women were living longer than men in all cities, but in Buenos Aires, Mexico City and Santiago, most of the women's additional years of life were lived with disabilities. For example, in Mexico City, a full $90 \%$ of the life expectancy 
Figure 2:

Prevalence of disability at ages 60 and older, by gender and city, 2000

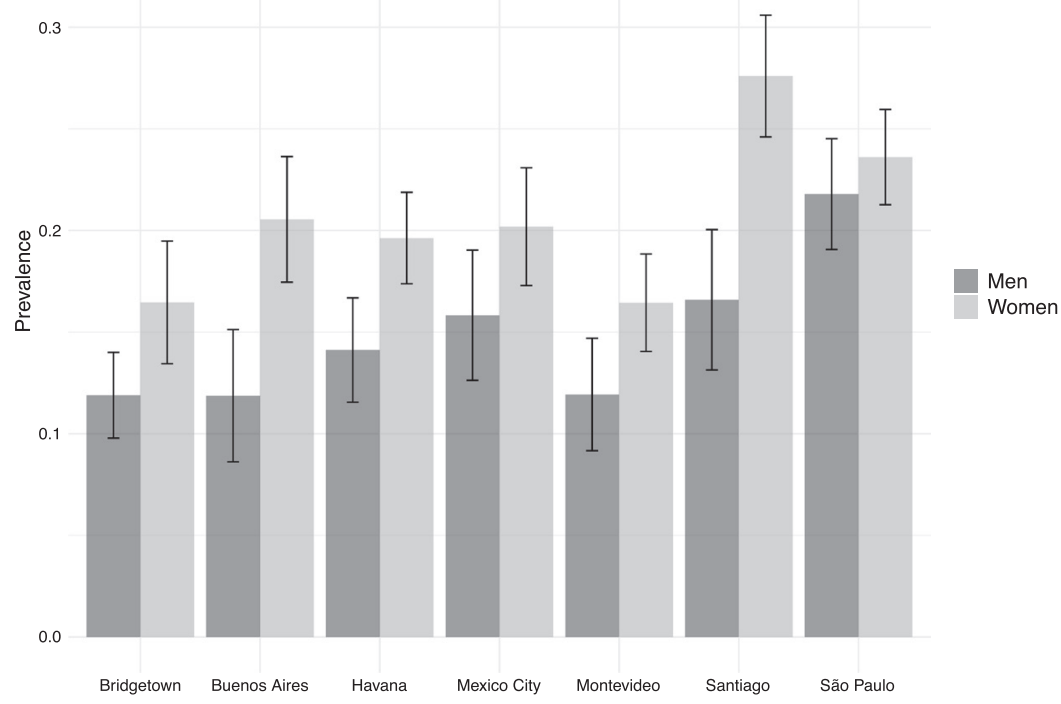

Note: Black segments correspond to a $95 \%$ confidence interval.

Source: Own elaboration using data from the SABE.

advantage of women was lived with disabilities. A similar pattern is observed in Santiago, although the number of years women were living with disabilities was much higher in Santiago (3.71) than in Mexico City (1.62). The comparison of the results in the two cities shows why focusing on only one gender gap health indicator can mask significant differences between cities. In Montevideo, Bridgetown and Havana, about $39 \%$ of women's additional years of life were spent with disabilities. In comparison, in São Paulo, 45\% of women's remaining years of life were spent with disabilities.

In all cities, both the disability and the mortality effects increased the gender gap in LEWD. In other words, women were living more years with disabilities because they were living longer and had higher rates of disability. The disability effects were larger than the mortality effects in Buenos Aires, Mexico City and Santiago; whereas the mortality effects were larger than the disability effects in Bridgetown, Havana, Montevideo and São Paulo.

The gender gap in disability-free life expectancy (DFLE) indicates that in absolute terms, women also enjoyed more healthy years of life than men in all cities. However, for Buenos Aires, Mexico City and Santiago, DFLE represented a smaller 
Table 2:

Decomposition of the gender gap (women-men) in total life expectancy (LE), disability-free life expectancy (DFLE) and life expectancy with disability (LEWD) into mortality and disability effects at age 60 (confidence intervals in brackets), by city, 2000

\begin{tabular}{|c|c|c|c|}
\hline & $\mathrm{LE}$ & DFLE & LEWD \\
\hline \multicolumn{4}{|c|}{ Bridgetown (Barbados) } \\
\hline Gender gap & 5.10 & $3.11(2.84 ; 3.37)$ & $1.99(1.73 ; 2.26)$ \\
\hline Mortality effect & 5.10 & $3.91(3.46 ; 4.34)$ & $1.20(0.76 ; 1.64)$ \\
\hline Disability effect & & $-0.80(-0.97 ;-0.62)$ & $0.80(0.62 ; 0.97)$ \\
\hline \multicolumn{4}{|c|}{ Buenos Aires (Argentina) } \\
\hline Gender gap & 4.60 & $1.82(1.57 ; 2.07)$ & $2.78(2.53 ; 3.03)$ \\
\hline Mortality effect & 4.60 & $3.38(2.81 ; 3.94)$ & $1.23(0.66 ; 1.79)$ \\
\hline Disability effect & & $-1.55(-1.87 ;-1.24)$ & $1.55(1.24 ; 1.87)$ \\
\hline \multicolumn{4}{|l|}{ Havana (Cuba) } \\
\hline Gender gap & 3.58 & $2.11(2.10 ; 2.13)$ & $1.47(1.45 ; 1.48)$ \\
\hline Mortality effect & 3.58 & $2.73(2.42 ; 3.04)$ & $0.85(0.54 ; 1.16)$ \\
\hline Disability effect & & $-0.61(-0.91 ;-0.32)$ & $0.61(0.32 ; 0.91)$ \\
\hline \multicolumn{4}{|c|}{ Mexico City (Mexico) } \\
\hline Gender gap & 1.80 & $0.18(0.09 ; 0.26)$ & $1.62(1.54 ; 1.71)$ \\
\hline Mortality effect & 1.80 & $1.22(1.02 ; 1.43)$ & $0.58(0.37 ; 0.78)$ \\
\hline Disability effect & & $-1.04(-1.32 ;-0.76)$ & $1.04(0.76 ; 1.32)$ \\
\hline \multicolumn{4}{|c|}{ Montevideo (Uruguay) } \\
\hline Gender gap & 5.30 & $3.28(3.05 ; 3.50)$ & $2.02(1.80 ; 2.25)$ \\
\hline Mortality effect & 5.30 & $4.17(3.64 ; 4.71)$ & $1.13(0.59 ; 1.66)$ \\
\hline Disability effect & & $-0.90(-1.21 ;-0.59)$ & $0.90(0.59 ; 1.21)$ \\
\hline \multicolumn{4}{|l|}{ Santiago (Chile) } \\
\hline Gender gap & 4.10 & $0.39(0.32 ; 0.46)$ & $3.71(3.64 ; 3.78)$ \\
\hline Mortality effect & 4.10 & $2.61(2.15 ; 3.06)$ & $1.50(1.04 ; 1.95)$ \\
\hline Disability effect & & $-2.21(-1.69 ;-2.74)$ & $2.21(2.74 ; 1.69)$ \\
\hline \multicolumn{4}{|l|}{ São Paulo (Brazil) } \\
\hline Gender gap & 4.70 & $2.59(2.34 ; 2.75)$ & $2.11(1.95 ; 2.36)$ \\
\hline Mortality effect & 4.70 & $3.18(2.85 ; 3.50)$ & $1.53(1.20 ; 1.85)$ \\
\hline Disability effect & & $-0.58(-0.75 ;-0.41)$ & $0.58(0.41 ; 0.75)$ \\
\hline
\end{tabular}

Source: Own elaboration using data from the SABE and Andrade (2009).

fraction of the gender gap in LE than LEWD. The largest gender gaps in DFLE occurred in cities where women's mortality advantage was substantial and surpassed women's disability disadvantage, which was the case in Bridgetown, Buenos Aires, Havana, Montevideo and São Paulo. In Mexico City, the combination of a high prevalence of disability among women ( -1.04 years) and a small women's mortality 
Figure 3:

Decomposition of the gender gap in disability-free life expectancy (DFLE) into mortality and disability effects by five-year age groups and city, 2000

Bridgetown (Barbados)

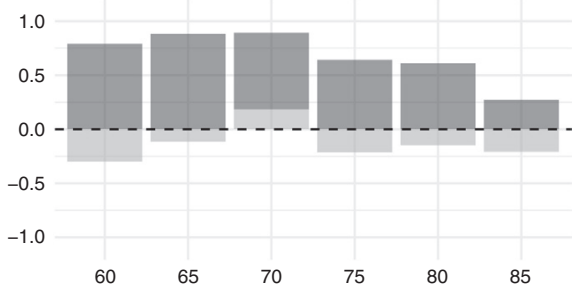

Havana (Cuba)

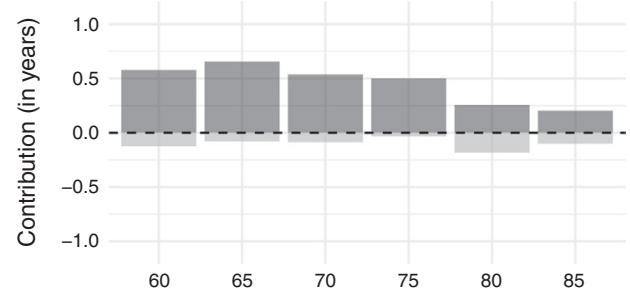

Montevideo (Uruguay)

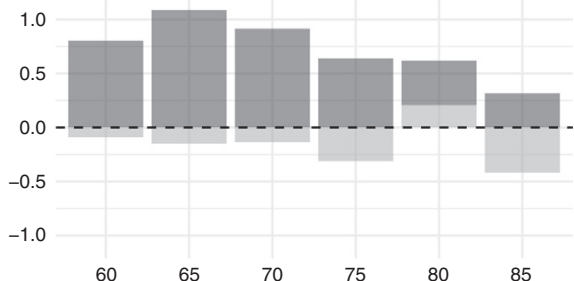

São Paulo (Brazil)

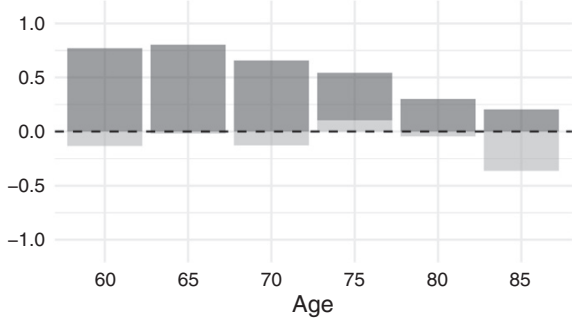

Buenos Aires (Argentina)

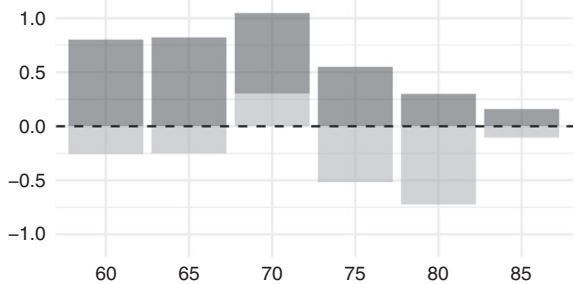

Mexico City (Mexico)

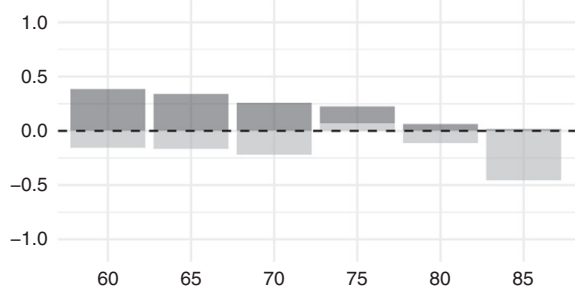

Santiago (Chile)

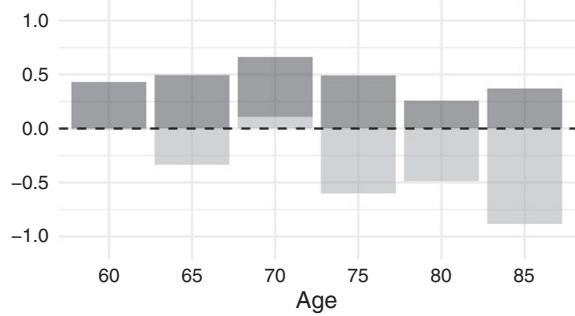

Source: Own elaboration using data from the SABE and Andrade (2009).

Component

Mortality

Disability 
advantage ( 1.22 years) resulted in men and women having nearly the same number of healthy years of life after age 60. In Santiago, the gender gap in DFLE was also close to zero ( 0.39 years). Figure 3 details the age decomposition of the gap in DFLE. As expected, the mortality effects - meaning more years of life - were higher among women in all age groups and across all cities. However, the mortality effects decreased almost systematically with age, which suggests that the contribution of gender differences in mortality to the gap in DFLE was lower at older ages. For instance, the mortality effects were more than $70 \%$ lower between ages 60 and $85+$ in Buenos Aires, Mexico City and São Paulo. In contrast, Figure 3 does not show a clear age pattern for the disability effects across the seven cities, although they tended to affect women's health measures negatively at most ages. There were, however, exceptions: in Buenos Aires and Santiago, the disability effects were positive in the 70-74 age group, which means that the prevalence rates of ADLs were higher among men than women. Still, the effects were negative at all other ages. Havana was the only city where women experienced higher levels of disability at all ages, but they were lower in magnitude than in the other LAC cities.

\section{Discussion}

Our results have confirmed that in Latin American and Caribbean cities in 2000, women were living longer than men, but were spending more years in poor health. These results are consistent with those of other studies that focused on gender differences in mortality and morbidity, not only in the LAC region, but worldwide (Camargos et al. 2007; Camargos et al. 2008; Andrade et al. 2011; Jagger and Matthews 2002; Oksuzyan et al. 2008; Palloni and McEniry 2007; Van Oyen et al. 2010; Wong et al. 2005; Yokota et al. 2019; Zunzunegui et al. 2009).

Although our findings indicate that the gender gap in health in terms of both disability-free life expectancy (DFLE) and life expectancy with disability (LEWD) followed a similar pattern within the region, its decomposition into the contribution of mortality and disability effects showed that there was substantial variation across cities, which suggests that the underlying mechanisms of the gender gap differed considerably. Our results highlight the importance of investigating not only the contributions of disability and mortality to the gender gap in DFLE, but also the years lived with disability. DFLE was higher for women than for men because women were living longer despite having a higher prevalence of disabilities. The women's disability disadvantage was not able to cancel out the women's mortality advantage in any of the cities in our sample, although it came close in Mexico City (Mexico) and Santiago (Chile). On the other hand, women were living more years with disability (LEWD) than men because of the combination of two effects: women were living longer and had higher rates of disability. In three of the cities - Buenos Aires (Argentina), Mexico City (Mexico) and Santiago (Chile) - the gender gap in LEWD represented a larger fraction of the total gender gap in life expectancy than DFLE. In São Paulo, DFLE and LEWD were comparable in size. In Bridgetown, 
Havana and Montevideo, the gender gap in DFLE represented a larger fraction of the gender gap in LE than LEWD.

There are many potential explanations for the patterns we observed across LAC countries. As was previously mentioned, the differences in Chile could be attributed to evidence suggesting that the prevalence of osteoporosis is five times higher among older women than men (Albala et al. 2011). In Mexico, the combination of a high prevalence of disability and lower mortality among women may be connected at least in part to the high shares of women who have diabetes, especially at ages 70-75 (29\%). Similarly, previous studies have shown that the mean BMI was higher for women than for men, and that the percentage of women with obesity was significantly higher than that of men $(26.7 \%$ vs. $22.3 \%)$ (Wong et al. 2015). Taken together, these factors could explain why in these cities, the gender gap in LEWD contributed more than DFLE to the total gender gap in life expectancy.

On the other hand, Brazil, Cuba, Uruguay and Barbados were found to be the countries where the women's mortality advantage contributed the most to the gender gap in the years lived with disabilities. As we previously noted, in Brazil, this may be related to the gender gap in mortality by disability severity, or to the levels of life-threatening gender-specific conditions. Compared to their male peers, Brazilian women live longer lives, but are more likely to be disabled, and to have severe disabilities (Camargos et al. 2008; Andrade et al. 2011). Thus, in Brazil, women at age 60 can expect to live two years longer with severe limitations than men at the same age (Belon et al. 2014; Nepomuceno and Turra 2012; Parahyba et al. 2005). Similarly, the gender gap in unhealthy life-years in Cuba may be due to the high prevalence levels of acute myocardial infarction among men, and to men's increased risk of dying from this cause relative to that of women of the same age (Armas et al. 2012), together with the higher lung cancer incidence and associated mortality risk among older men (Galán et al. 2009). Surprisingly, the finding that in Uruguay the women's mortality advantage contributed to the gender gap in life years lived with disability may be due to a stronger disadvantage in mortality among men than to a mortality advantage among women. As estimates in Figure 1 showed, the remaining life expectancy at age 60 for women in Montevideo (Uruguay) was the second-highest among all of the cities in the sample (approximately 23 years), but the remaining life expectancy at age 60 for men was the third-lowest for all of the cities (approximately 18 years). Thus, further investigation is needed to understand the low remaining LE at age 60 among men, given the high remaining LE among women of the same age. It is also noteworthy that Uruguay had one of the lowest rates of response in the SABE $(66 \%)$, while the rates for the other countries varied between $85 \%$ and $95 \%$. It is unclear whether this lower response rate could have biased some of the results. However, the fact that the socioeconomic indicators were better for Uruguay than for the other countries suggests that the lower disability effects found in Uruguay were not mainly attributable to response rates.

Finally, we should note that reports on the SABE have mentioned that Uruguay is the only country included in the SABE where the proportion of older people living in institutions is higher than it is in the other countries. Since the SABE samples are 
household-based and exclude those in institutions, there may be a selection among those who remain independent instead of becoming institutionalized that affects the health measures (Palloni and McEniry 2007). However, since the main source of long-term care services in LAC is unpaid care that family members, primarily women, provide to care-dependent older people, it is unlikely that this issue played an important role in our results. Indeed, in all seven cities in our sample, the shares of older adults living alone were lower than the shares in North America and Western Europe (Palloni et al. 2002; DeVos and Palloni 2002).

In Bridgetown (Barbados), like in Montevideo (Uruguay), our findings that there was a large gender gap in life expectancy, and that a large proportion of the gap was spent without disability (61\%), may be attributable to a larger male disadvantage, since it has been reported that the region has struggled in the past decade with a very large burden of deaths from liver cirrhosis attributed to alcohol abuse and heavy smoking among men (Moonie and Quashie 2011).

Explanations for these contradictory findings regarding health and mortality among women and men - or the so-called health-survival paradox - have been mainly developed from the perspective of excess mortality among males (due to biological and acquired risks) or excess disability among females (due to types and severity of illnesses and disability, illness and prevention orientation and health reporting behavior). The evidence for these explanations is still inconclusive and conflicting, with studies showing either that male excess mortality is more important or that female excess morbidity is the more prominent factor (Austad 2006; Austad 2011; Grundy 2006).

Our work adds to this body of literature by showing that such an ambiguous relationship was not only present in the Latin American and the Caribbean context, but also that the relative contributions of women's morbidity and men's mortality varied substantially throughout the region. The results suggest that policy-makers seeking to address health inequalities should consider not only the total gender gap, but also whether those differences are related to health or mortality factors.

\section{Acknowledgements}

This study was supported by the European Research Council within the EU Framework Programme for Research and Innovation Horizon 2020, ERC Grant Agreement No. 716323; the European Research Council within the EU Framework Programme for Research and Innovation Horizon 2020, ERC Grant Agreement No. 725187 (LETHE); the Brazilian Graduate Studies Coordinating Board (Capes, Code 001), which funds the Demography Program at the Federal University of Minas Gerais; and the Brazilian National Research Council (CNPq). 


\section{References}

Albala, C., M. L. Lebrao, E. M. Léon Díaz, R. Ham-Chande, A. J. Hennis, A. Palloni, M. Peláez and O. Pratts 2005. The health, well-being, and aging ("SABE") survey: Methodology applied and profile of the study population. Revista Panamericana de Salud Publica/Pan American Journal of Public Health 17: 307-322. https://doi.org/10.1590/ s1020-49892005000500003

Albala, C., H. Sánchez, L. Lera, B. Angel and X. Cea 2011. Efecto sobre la salud de las desigualdades socioeconómicas en el adulto mayor. Resultados basales del estudio expectativa de vida saludable y discapacidad relacionada con la obesidad (Alexandros). Revista Medica de Chile 139: 1276-1285. https://doi.org/10.4067/S003498872011001000005

Acosta, E., C. Torres, R. Silva-Ramírez and R. Bourbeau 2018. Violence and mortality from external causes in Colombia: Analysis of demographic costs during the period 1979-2016. Paper presented at the VIII Congresso de La Asociación Latinoamericana de Poblacíon, Mexico - Puebla 2018. http://www.alapop.org/Congreso2018/PDF/0021a.pdf

Andrade, F. C. D., P. E. Guevara, M. L. Lebrão, Y. A. de Oliveira Duarte and J. L. F. Santos 2011. Gender differences in life expectancy and disability-free life expectancy among older adults in São Paulo, Brazil. Women's Health Issues 21: 64-70. https://doi.org/10. 1016/j.whi.2010.08.007

Andrade, F. 2009. Estimating diabetes and diabetes-free life expectancy in Mexico and seven major cities in Latin America and the Caribbean. Revista Panamericana de Salud Publica/Pan American Journal of Public Health 26(1): 9-16. https://doi.org/10.1590/ s1020-49892009000700002

Andrade, F. C. D., L. P. Corona, M. L. Lebrão and Y. A. O. de Duarte 2014. Life expectancy with and without cognitive impairment among Brazilian older adults. Archives of Gerontology and Geriatrics 58(2): 219-225. https://doi.org/10.1016/j.archger.2013.10.007

Angel, J. L., W. Vega, M. López-Ortega and R. Pruchno 2017. Aging in Mexico: Population trends and emerging issues. Gerontologist 57(2): 153-162. https://doi.org/10.1093/geront/ gnw136

Armas, N. B., Y. Y. Ortega, R. de la Noval, R. Suárez, L. Llerena and A. F. Dueñas 2012. Acute myocardial infarction mortality in Cuba, 1999-2008. MEDICC Review 14: 19-25. https://doi.org/10.37757/MR2012V14.N4.6

Austad, S. N. 2011. Sex differences in longevity and aging. In: Handbook of the Biology of Aging, eds E. J. Masoro and S. N. Austad, 479-495. Academic Press. https://doi.org/10. 1016/B978-0-12-378638-8.00023-3

Austad, S. N. 2006. Why women live longer than men: Sex differences in longevity. Gender Medicine 3(2): 79-92. https://doi.org/10.1016/S1550-8579(06)80198-1

Barbosa, A. R., J. M. P. Souza, M. L. Lebrão, R. Laurenti and M. de Fátima Nunes Marucci 2005. Functional limitations of Brazilian elderly by age and gender differences: data from SABE Survey. Cadernos de Saúde Pública/Reports in Public Health 21: 1177-1185. https://doi.org/10.1590/S0102-311X2005000400020 
Barragán-Martínez, C., J. Amaya-Amaya, R. Pineda-Tamayo, R. D. Mantilla, J. CastellanosDe La Hoz, S. Bernal-Macías, A. Rojas-Villarraga and J. M. Anaya 2012. Gender differences in latin-american patients with rheumatoid arthritis. Gender Medicine 9(6): 490-510.e5. https://doi.org/10.1016/j.genm.2012.10.005

Beckett, L. A., D. B. Brock, J. H. Lemke, C. F. Mendes de Leon, J. M. Guralnik, G. G. Fillenbaum, L. G. Branch, T. T. Wetle and D. Evans 1996. Analysis of change in selfreported physical function among older persons in four population studies. American Journal of Epidemiology 143(8): 766-78. https://doi.org/10.1093/oxfordjournals.aje. a008814

Belon, A. P., M. G. Lima and M. B. A. Barros 2014. Gender differences in healthy life expectancy among Brazilian elderly. Health Quality Life Outcomes 12(88). https://doi. org/10.1186/1477-7525-12-88

Camargos, M. C. S., C. J. Machado and R. N. Rodrigues 2007. Disability life expectancy for the elderly, city of São Paulo, Brazil, 2000: Gender and educational differences. Journal of Biosocial Science 39(3): 455-463. https://doi.org/10.1017/S0021932006001428

Camargos, M. C. S., C. J. Machado and R. N. Rodrigues 2008. Life expectancy among elderly Brazilians in 2003 according to different levels of functional disability. Cadernos de Saúde Pública/Reports in Public Health 24: 845-852. https://doi.org/10.1590/S0102311X2008000400015

Campos, A. C. V., C. Albala, L. Lera, H. Sánchez, A. M. D. Vargas and E. F. E. Ferreira 2015. Gender differences in predictors of self-rated health among older adults in Brazil and Chile. BMC Public Health 15(365): 1-11. https://doi.org/10.1186/s12889-015-1666-9

Canudas-Romo, V. and J. M. Aburto 2019. Youth lost to homicides: Disparities in survival in Latin america and the caribbean. BMJ Global Health 4(2). https://doi.org/10.1136/bmjgh2018-001275

Case, A. and C. Paxson 2005. Sex differences in morbidity and mortality. Demography 42: 189-214. https://doi.org/10.1353/dem.2005.0011

Costa Filho, A. M., J. Vaz de Melo Mambrini, D. C. Malta, M. F. Lima-Costa and S. V. Peixoto 2018. Contribution of chronic diseases to the prevalence of disability in basic and instrumental activities of daily living in elderly Brazilians: The National Health Survey 2013. Cadernos de Saúde Pública/Reports in Public Health 34: 1-12. https: //doi.org/10.1590/0102-311x00204016

Crimmins, E. M., M. D. Hayward and Y. Saito 1996. Differentials in active life expectancy in the older population of the United States. The Journal of Gerontology: Series B 51B(3): S111-S120. https://doi.org/10.1093/geronb/51B.3.S111

Crimmins, E. M. and J. K. Kim 2010. Gender differences in health: Results from SHARE, ELSA and HRS. European Journal of Public Health 21: 81-91. https://doi.org/10.1093/ eurpub/ckq022

Crimmins, E. M., J. K. Kim and A. Hagedorn 2002. Life with and without disease: Women experience more of both. Journal of Women $\mathcal{F}$ Aging 14(1-2): 47-59. https://doi.org/10. 1300/J074v14n01_04

Crimmins, E. M. and Y. Saito 2001. Trends in healthy life expectancy in the United States, 1970-1990: Gender, racial, and educational differences. Social Science and Medicine 52: 1629-41. https://doi.org/10.1016/s0277-9536(00)00273-2 
Crimmins, E. M., Y. Zhang and Y. Saito 2016. Trends over 4 decades in disability-free life expectancy in the United States. American Journal of Public Health 106(7): 1287-1293. https://doi.org/10.2105/AJPH.2016.303120

DeVos, S. and A. Palloni 2002. Living arrangements of elderly people around the world. Madison: University of Wisconsin-Madison, Center for Demography \& Ecology.

di Lego, V., P. Di Giulio and M. Luy 2020. Gender differences in healthy and unhealthy life expectancy. International Handbook of Health Expectancies. International Handbooks of Population, eds C. Jagger, E. M. Crimmins, Y. Saito, R. T. C. Yokota, H. Van Oyen and J.-M. Robine, 151-172. Cham: Springer. https://doi.org/10.1007/978-3-030-37668-0_11

Duarte, Y. A. O. D, M. L. Lebrão, F. D. Lima 2005. Contribuição dos arranjos domiciliares para o suprimento de demandas assistenciais dos idosos com comprometimento functional em São Paulo, Brasil. Panamericana de Salud Publica/Pan American Journal of Public Health. 17(5/6): 370-378.

Franco, M., J. F. Kennelly, R. S. Cooper and P. Ordúñez-García 2007a. Health in Cuba and the millennium development goals. Revista Panamericana de Salud Publica/Pan American Journal of Public Health 21: 239-250. https://doi.org/10.1590/s102049892007000300007

Franco, M., P. Orduñez, B. Caballero, J. A. Tapia Granados, M. Lazo, J. L. Bernal, E. Guallar and R. S. Cooper 2007b. Impact of energy intake, physical activity, and populationwide weight loss on cardiovascular disease and diabetes mortality in Cuba, 1980-2005. American Journal of Epidemiology 166(12): 1374-1380. https://doi.org/10.1093/aje/ kwm226

Galán, Y., L. Fernández, P. Torres and M. García 2009. Trends in Cuba's cancer incidence (1990 to 2003) and mortality (1990 to 2007). MEDICC Review 11(3): 19-26. https: //doi.org/10.37757/MR2009V11.N3.6

Gorman, B.K. and J. G. Read 2006. Gender disparities in adult health: An examination of three measures of morbidity. Journal of Health and Social Behavior 47(2): 95-110. https://doi.org/10.1177/002214650604700201

Green, C. A. and C. R. Pope 1999. Gender, psychosocial factors and the use of medical services: A longitudinal analysis. Social Science and Medicine 48(10): 1363-72. https: //doi.org/10.1016/S0277-9536(98)00440-7

Grundy, E. 2006. Gender and healthy aging. In: Longer Life and Healthy Aging, eds Y. Zeng, E. M. Crimmins, Y. Carriere and J.-M. Robine, 173-199. Dordrecht: Springer. https: //doi.org/10.1007/1-4020-4032-6_12

Guh, D. P., W. Zhang, N. Bansback, Z. Amarsi, C. L. Birmingham and A. H. Anis 2009. The incidence of co-morbidities related to obesity and overweight: A systematic review and meta-analysis. BMC Public Health 9: 88. https://doi.org/10.1186/1471-2458-9-88

Hennis, A., I. Hambleton, H. Broome, S. Crichlow and H. Fraser 2005. Health, welfare and aging in Bridgetown, Barbados: SABE 2000. Pan American Health Organization.

Horiuchi, S., J. R. Wilmoth, and S. D. Pletcher 2008. A decomposition method based on a model of continuous change. Demography 45: 785-801. https://doi.org/10.1353/dem.0. 0033 
Huenchuan, S. 2013. Ageing, solidarity and social protection in Latin America and the Caribbean: Time for progress towards equality. Libros de la CEPAL, 117. https: //repositorio.cepal.org/handle/11362/2620

International Health Conference. 2002. Constitution of the World Health Organization. 1946. Bulletin of the World Health Organization 80(12): 983-984. World Health Organization. https://apps.who.int/iris/handle/10665/268688

Jacobsen, R., A. Oksuzyan, H. Engberg, B. Jeune, J. W. Vaupel and K. Christensen 2008. Sex differential in mortality trends of old-aged Danes: A nation wide study of age, period and cohort effects. European Journal of Epidemiology 23(11): 723-730. https: //doi.org/10.1007/s10654-008-9288-5

Jagger, C. and F. Matthews 2002. Gender differences in life expectancy free of impairment at older ages. Journal of Women $\mathcal{F}$ Aging 14: 85-97. https://doi.org/10.1300/J074v14n01_06

Kearns, K., A. Dee, A. P. Fitzgerald, E. Doherty and I. J. Perry 2014. Chronic disease burden associated with overweight and obesity in Ireland: The effects of a small BMI reduction at population level. BMC Public Health 14(143). https://doi.org/10.1186/1471-2458-14-143

Keevil, V. L., S. Hayat, N. Dalzell, S. Moore, A. Bhaniani, R. Luben, N. J. Wareham and K.-T. Khaw 2013. The physical capability of community-based men and women from a British cohort: The European Prospective Investigation into Cancer (EPIC)-Norfolk study. BMC Geriatrics 13(93). https://doi.org/10.1186/1471-2318-13-93

Knight, F. W., J. Sued Badillo, K. O. Laurence, J. Ibarra, B. Brereton and B. W. Higman 2004. General history of the Caribbean. Volume 5, Unesco.

Kulminski, A. M., I. V. Culminskaya, S. V. Ukraintseva, K. G. Arbeev, K. C. Land and A. I. Yashin 2008. Sex-specific health deterioration and mortality: The morbidity-mortality paradox over age and time. Experimental Gerontology 43(12): 1052-1057. https://doi.org/ 10.1016/j.exger.2008.09.007

Leong, D. P., K. K. Teo, S. Rangarajan, P. Lopez-Jaramillo, A. Avezum, A. Orlandini, P. Seron, S. H. Ahmed, A. Rosengren, R. Kelishadi, O. Rahman, S. Swaminathan, R. Iqbal, R. Gupta, S. A. Lear, A. Oguz, K. Yusoff, K. Zatonska, J. Chifamba, E. Igumbor, V. Mohan, R. M. Anjana, H. Gu, W. Li and S. Yusuf 2015. Prognostic value of grip strength: Findings from the Prospective Urban Rural Epidemiology (PURE) study. Lancet 386(9990): 266-273. https://doi.org/10.1016/S0140-6736(14)62000-6

Lebrão, M. L., Y. A. O. Duarte, J. L. F. S. Santos and N. N. Silva 2018. 10 years of SABE Study: Background, methodology and organization of the study. Revista Brasileira de Epidemiologia 21(2). https://doi.org/10.1590/1980-549720180002.supl.2

Luy, M. and Y. Minagawa 2014. Gender gaps-Life expectancy and proportion of life in poor health. Health Reports 25(12): 12-9.

Mairey, I., P. Bjerregaard and H. Brønnum Hansen 2014. Gender difference in health expectancy trends in Greenland. Scandinavian Journal of Public Health 42(8): 751-758. https://doi.org/10.1177/1403494814550174

Mathers, C., J. Salomon and A. Tandon 2001. Estimates of healthy life expectancy for 191 countries in the year 2000: Methods and results. World Health Organization 2001.

Monteverde, M., K. Noronha and A. Palloni 2009. Effect of early conditions on disability among the elderly in Latin America and the Caribbean. Population Studies 63(1): 21-35. https://doi.org/10.1080/00324720802621583 
Moonie, S. and N. Quashie 2011. Social health protection for the elderly in the Englishspeaking Caribbean. Series Studies and Perspectives de la CEPAL. https://repositorio. cepal.org/bitstream/handle/11362/5052/1/S2012131_en.pdf

Moreno, X., C. Albala, L. Lera, B. Leyton, B. Angel and H. Sánchez 2018. Gender, nutritional status and disability-free life expectancy among older people in Santiago, Chile. PLoS ONE 13(3). https://doi.org/10.1371/journal.pone.0194074

Murray, C. J. L., J. A. Salomon, C. D. Mathers, P. J. Van Der Maas, A. D. Lopez and J. Richardson 2002. Summary Measures of Population Health: Concepts, Ethics, Measurement and Applications. Geneva: World Health Organization. https://apps.who.int/ iris/handle/10665/42439

Murtagh, K. N. and H. B. Hubert 2004. Gender differences in physical disability among an elderly cohort. American Journal of Public Health 94(8): 1406-1411. https://doi.org/10. 2105/AJPH.94.8.1406

Nepomuceno, M. R. and C. M. Turra 2012. Expectativa de vida saudável no Brasil com base no método intercensitário. In: Anais do V Congresso de La Asociación Latinoamericana de Poblacíon, Montevideo, Uruguay, 23-26 October 2012 http://www. alapop.org/Congreso2012/DOCSFINAIS_PDF/ALAP_2012_FINAL479.pdf

Noronha, K. V. M. and M. A. Viegas 2005. Social inequality in health and the utilization of health services among the elderly in Latin America. Revista Panamericana de Salud Publica/Pan American Journal of Public Health 17: 410-418. https://doi.org/10.1590/ s1020-49892005000500013

Nusselder, W. J. and C. W. N. Looman 2004. Decomposition of differences in health expectancy by cause. Demography 41: 315-334. https://doi.org/10.1353/dem.2004.0017

Nusselder, W. J., C. W. N. Looman, H. van Oyen, J. M. Robine and C. Jagger 2010. Gender differences in health of EU10 and EU15 populations: The double burden of EU10 men. European Journal of Ageing 7: 219-227. https://doi.org/10.1007/s10433-010-0169-x

Oksuzyan, A., H. Brønnum-Hansen and B. Jeune 2010. Gender gap in health expectancy. European Journal of Ageing 7(4): 213-218. https://doi.org/10.1007/s10433-010-0170-4

Oksuzyan, A., K. Juel, J. W. Vaupel and K. Christensen 2008. Men: Good health and high mortality. Sex differences in health and aging. Aging Clinical and Experimental Research 20(2): 91-102. https://doi.org/10.1007/BF03324754

Oksuzyan, A., M. Shkolnikova, J. W. Vaupel, K. Christensen and V. M. Shkolnikov 2014. Sex differences in health and mortality in Moscow and Denmark. European Journal of Epidemiology 29: 243-252. https://doi.org/10.1007/s10654-014-9893-4

Palloni, A. and M. McEniry 2007. Aging and health status of elderly in Latin America and the Caribbean: Preliminary findings. Journal of Cross-Cultural Gerontology 22: 263-285. https://doi.org/10.1007/s10823-006-9001-7

Palloni, A., G. Pinto-Aguirre and M. Pelaez 2002. Demographic and health conditions of ageing in Latin America and the Caribbean. International Journal of Epidemiology 31: 762-771. https://doi.org/10.1093/ije/31.4.762

Parahyba, M. I., R. Veras and D. Melzer 2005. Disability among elderly women in Brazil. Revista de Saude Publica 39: 383-391. https://doi.org/10.1590/s003489102005000300008 
Pelaez, M., A. Palloni, C. Albala, J. C. Alfonso, R. Ham-Chande, A. Hennis and O. Prats 2006. SABE-Survey on Health, Well-Being, and Aging in Latin America and the Caribbean. Ann Arbor, MI: Inter-university Consortium for Political and Social Research [distributor], 17 February 2006. https://doi.org/10.3886/ICPSR03546.v1

Redondo-Sendino, Á., P. Guallar-Castillón, J. Banegas and F. Rodríguez-Artalejo 2006. Gender differences in the utilization of health-care services among the older adult population of Spain. BMC Public Health 6: 155. https://doi.org/10.1186/1471-2458-6-155

Rieker, P. P. and C. E. Bird 2005. Rethinking gender differences in health: Why we need to integrate social and biological perspectives. Journals Gerontology Serie B 60B: 40-47. https://doi.org/10.1093/geronb/60.Special_Issue_2.S40

Riffe, T. 2018. DemoDecomp: Decompose Demographic Functions. R Package version 101. https://cran.r-project.org/web/packages/DemoDecomp/DemoDecomp.pdf

Robine, J.-M., C. Jagger and I. Romieu 2001. Disability-free life expectancies in the European Union countries: calculation and comparisons. Genus 57: 89-101. https://www.jstor.org/ stable/29788693

Robine, J.-M. and J. W. Vaupel 2001. Supercentenarians: Slower ageing individuals or senile elderly? Experimental Gerontology 36(4-6): 915-930. https://doi.org/10.1016/S05315565(00)00250-3

Robine, J., Y. Saito and C. Jagger 2009. The relationship between longevity and healthy life expectancy. Quality in Ageing and Older Adults 10(2): 5-14. https://doi.org/10.1108/ 14717794200900012

Roe, C. M., A. M. McNamara and B. R. Motheral 2002. Gender- and age-related prescription drug use patterns. Annals of Pharmacotherapy 36(1): 30-39. https://doi.org/10.1345/aph. $1 \mathrm{~A} 113$

Sanderson, W. C. and S. Scherbov 2014. Measuring the speed of aging across population subgroups. PLoS ONE 9: 3-6. https://doi.org/10.1371/journal.pone.0096289

Spiers, N., C. Jagger, M. Clarke and A. Arthur 2003. Are gender differences in the relationship between self-rated health and mortality enduring? Results from three birth cohorts in Melton Mowbray, United Kingdom. Gerontologist 43(3): 406-411. https://doi.org/10. 1093/geront/43.3.406

Sullivan, D. 1971. A single index of mortality and morbidity. HSMHA Health Reports 86: 347-54.

Turra, C. M. and F. Fernandes 2020. Demographic transition: Opportunities and challenges to achieve the Sustainable Development Goals in Latin America and the Caribbean, Project Documents, (LC/TS.2020/105), Santiago, Economic Commission for Latin America and the Caribbean (ECLAC).

UNECE/European Commission 2015. Active Ageing Index 2014: Analytical Report.

United Nations, Department of Economic and Social Affairs, Population Division 2019. World Population Prospects 2019. https://population.un.org/wpp/

United Nations, Department of Economic and Social Affairs, Population Division 2017. World Population Ageing 2017. https://www.un.org/en/development/desa/population/ theme/ageing/WPA2017.asp

United Nations Development Programme 2015. Transforming our world: The 2030 Agenda for Sustainable Development. https://sdgs.un.org/2030agenda 
Van Oyen, H., B. Cox, C. Jagger, E. Cambois, W. Nusselder, C. Gilles and J.-M. Robine 2010. Gender gaps in life expectancy and expected years with activity limitations at age 50 in the European Union: Associations with macro-level structural indicators. European Journal of Ageing 7: 229-237. https://doi.org/10.1007/s10433-010-0172-2

Van Oyen, H., W. Nusselder, C. Jagger, P. Kolip, E. Cambois and J.-M. Robine 2013. Gender differences in healthy life years within the E.U.: An exploration of the "health-survival" paradox. International Journal of Public Health 58: 143-155. https://doi.org/10.1007/ s00038-012-0361-1

van Raalte, A. A. and M. R. Nepomuceno 2020. Decomposing gaps in healthy life expectancy. In: International handbook of health expectancies. International handbooks of population, eds C. Jagger, E. M. Crimmins, Y. Saito, R. T. C. Yokota, H. Van Oyen and J.-M. Robine, 107-122. Cham: Springer. https://doi.org/10.1007/978-3-030-37668-0_7

Verbrugge, L. M. 1989. The twain meet: Empirical explanations of sex differences in health and mortality. Journal of Health and Social Behavior 30(3): 282-304. https://psycnet.apa. org/doi/10.2307/2136961

Verbrugge, L. M. 1985. Gender and health: An update on hypotheses and evidence. Journal of Health and Social Behavior 26(3): 156-182. https://doi.org/10.2307/2136750

Wallace, S. P. and V. F. Gutiérrez 2005. Equity of access to health care for older adults in four major Latin American cities. Revista Panamericana de Salud Publica/Pan American Journal of Public Health 17: 394-409. https://doi.org/10.1590/S1020-49892005000500012

Wang, Z., Y. Zeng, B. Jeune and J. W. Vaupel 1998. Age validation of Han Chinese centenarians. Genus 54: 123-41. https://www.jstor.org/stable/29788544

Wong, R., A. Michaels-Obregon, A. Palloni, L. M. Gutierrez-Robledo, C. Gonzalez-Gonzalez, M. Lopez-Ortega and M. M. Tellez-Rojo 2015. Progression of aging in Mexico: The Mexican Health and Aging Study (MHAS) 2012. Salud Publica de Mexico 57: S79-S89. https://doi.org/10.21149/spm.v57s1.7593

Wong, R., M. Peláez and A. Palloni 2005. Self-reported general health in older adults in Latin America and the Caribbean: Usefulness of the indicator. Revista Panamericana de Salud Publica/Pan American Journal of Public Health 17: 323-332. https://doi.org/10. 1590/s1020-49892005000500004

World Health Organization. 2004. International plan of action on ageing: Report on implementation report by the secretariat. https://apps.who.int/gb/archive/pdf_files/EB115/ B115_29-en.pdf

Yokota, R. T. C., W. J. Nusselder, J.-M. Robine, J. Tafforeau, F. Renard, P. Deboosere and H. Van Oyen 2019. Contribution of chronic conditions to gender disparities in health expectancies in Belgium, 2001, 2004 and 2008. European Journal of Public Health 29: 82-87. https://doi.org/10.1093/eurpub/cky105

Yong, V., Y. Saito and A. Chan 2010. Changes in the prevalence of mobility limitations and mobile life expectancy of older adults in Singapore, 1995-2005. Journal of Aging and Health 22(1): 120-140. https://doi.org/10.1177/0898264309351932

Zunzunegui, M. V., B. E. Alvarado, F. Béland and B. Vissandjee 2009. Explaining health differences between men and women in later life: A cross-city comparison in Latin America and the Caribbean. Social Science and Medicine 68: 235-242. https://doi.org/10. 1016/j.socscimed.2008.10.031 
Open Access This article is published under the terms of the Creative Commons Attribution 4.0 International License (https://creativecommons.org/licenses/by/4.0/) that allows the sharing, use and adaptation in any medium, provided that the user gives appropriate credit, provides a link to the license, and indicates if changes were made. 